\title{
Nutritional Properties of Probiotics with Prebiotics and Their Potential to Impact on Mineral Absorption and Immunological Status in Vivo
}

\author{
Hanaa, H. Elsayed ${ }^{1}$ and Sherif S. Ragab ${ }^{2}$ \\ ${ }^{I}$ Department of nutrition Biochemistry and metabolism, National Nutrition Institute, Cairo, Egypt. \\ ${ }^{2}$ Nutrition and food Science Dept., Home economics faculty, Menofia University, Egypt
}

\begin{abstract}
Functional foods or functional food ingredients exert a beneficial effect on host health and/or reduce the risk of chronic disease beyond their nutritive value.Probiotics are living microbial food components that beneficially affect the host by improving its intestinal microbial balance.Prebiotics are indigestible food ingredients that beneficially affect the host by selectively stimulating the growth and/or activity of one or a number of health-promoting colon bacteria and thus improve host health. This study suggested evaluatesLactobacillus acidophilus strain as probiotic and inulin (fructooligosaccharides) as prebiotic on mineral absorption and immunological status. Male Westar rats $(n=30)$, with an initial mean weight of 170 $\pm 10 \mathrm{~g}$,After 5 days as adaptation period, rats were randomly divided into three groups, a control group, a FOS group and FOS with probiotic bacteria (Lactobacillus acidophilus) group ( $n=10$ of each group). The diet in the FOS and FOS with Lactobacillus acidophilus groups contained $5 \mathrm{~g} / 100 \mathrm{~g}$ inulin and $2.5 \mathrm{~g} / 100 \mathrm{~g}$ diet respectively, through replacement of the sucrose in the control diet. The respective wet diets were dried for $1 \mathrm{~d}$ $\left(80^{\circ} \mathrm{C}\right)$ to calculate the wet/dry ratio, and calcium concentrations in the dry diets were then measured.A mineral metabolic study was performed to determine apparent calcium and magnesium absorptions in the intestine. They were determined in feces. Minerals concentrations (Ca, $\mathrm{Mg}$, and $\mathrm{P})$ in local bone areas were measured. Serum anti-sporidiumIgG and IgM were determined by ELISA standard technique. The results showed both calcium and magnesium apparent absorption was slightly but significantly greater in rats fed the fructooligosaccharides (FOS) with probiotic bacteria. All evaluate immunological parameter showed that group rat fed inline and Lactobacillus acidophilus strain was significant compare control group and group fed only inulin. Probiotic and prebiotic with together may improve absorption mineral special $\mathrm{Ca}$ and $\mathrm{Mg}$. Also ameliorate immunological status.
\end{abstract}

Keywords: Probiotic - Prebiotic-Mineral Absorption - Immunological

\section{Introduction}

Probiotics are micro-organisms that some have claimed provide health benefits when consumed. Lactic acid bacteria (LAB) and bifidobacteria are the most common types of microbes used as probiotics, but certain yeasts and bacilli may also be used [1]. Probiotics are live microbes that can be formulated into many different types of products, including foods, drugs, and dietary supplements [2].

Many probiotic supplements contain anywhere from 1 to 30 billion probiotic cells and often contain multiple strains [3]. However, not all probiotic strains provide the same health benefits and not all probiotic strains survive conditions inherent in food manufacturing [4], placing even greater importance on the selection of viable probiotics for food formulations.

Probiotics are commonly consumed as part of fermented foods with specially added active live cultures, such as in yogurt, soy yogurt, or as dietary supplements. Research into the potential health effects of supplemental probiotics has included the molecular biology and genomics of Lactobacillus in immune function, cancer, and antibiotic-associated diarrhea, travellers' diarrhea, pediatric diarrhea, inflammatory bowel disease and irritable bowel syndrome[5].

When a person takes antibiotics, both the harmful bacteria and the beneficial bacteria are killed. A reduction of beneficial bacteria can lead to digestive problems, such as diarrhea, yeast infections and urinary tract infections. The possibility that supplemental probiotics affect such digestive issues is unknown, and remains under study [6].

Probiotics may influence the immune system remains unclear, but a potential mechanism under research concerns the response of $\mathrm{T}$ lymphocytes to pro-inflammatory stimuli[7]. At $\mathbf{2 0 1 0}$ study suggested that probiotics, by introducing "good" bacteria into the gut, may help maintain immune system activity, which in turn helps the body react more quickly to new infections. Antibiotics seem to reduce immune system activity as a result of killing off the normal gut bacteria [8]. 
Through 2012, however, in all cases proposed as health claims to the European Food Safety Authority, the scientific evidence remains insufficient to prove a cause and effect relationship between consumption of probiotic products and any health benefit [9].

Prebiotics are non-digestible food ingredient that benefits the host by selectively stimulating the favorable growth and/or activity of 1 or more indigenous probiotic bacteria [10].

Prebiotics are dietary substances (mostly consisting of non-starch polysaccharides and oligosaccharides poorly digested by human enzymes) that nurture a selected group of microorganisms living in the gut. They favor the growth of beneficial bacteria over that of harmful ones. Unlike probiotics, most prebiotics are used as food ingredients - in biscuits, cereals, chocolate, spreads, and dairy products for example. Commonly known prebiotics are Oligofructose, Inulin, Galacto-oligosaccharides and Lactulose [11].

Fructooligosaccharides (FOS), a subgroup of inulin, is also a prebiotic and is often added to dairy foods and baked goods [12].

Japanese researchers also recognized the value of oligosaccharides in human milk and later demonstrated that consumption of fructooligosaccharides and galacto-oligosaccharides led to an increase in intestinal bifidobacteria and stimulated their growth in the human gut [13]. The increase in colonic bifidobacteria has been assumed to benefit human health by producing compounds to inhibit potential pathogens, by reducing blood ammonia levels, and by producing vitamins and digestive enzymes [11]. A prebiotic may be defined as "a selectively fermentedingredient that results in specific changes in the composition and/or activity of the gastrointestinal microbiota, thus conferring benefit(s) upon host health" [13].

This works aimed to assess the synergistic role of ingested probiotic bacteria with oligosaccharides on increases the mineral absorption and improve the general immunological status in rats.

\section{Material and Methods}

- Inulin (Fructooligosaccharides) was purchased from Better Life Co., for Food Supplement and Health Products (Tustin Avenue, Santa Ana, USA).

\section{- Probiotic Microorganism:}

Lactobacillus acidophilus strain (ATCC 4356) was obtained from the culture collection of the Department of Microbiology, Institute for Microbiology, Hannover University, and Hannover, Germany). The bacterial strain was grown in Rogosa and Sharp broth (Oxoid Hampshire, UK) for $18-22 \mathrm{~h}$ at $37^{\circ} \mathrm{C}$. After cultivation, bacteria were harvested by centrifugation $(5 \mathrm{~min}, 2000 \mathrm{rpm})$ and washed three times with sterile saline then evaporate the saline and dry the bacterial sediment. The growing process of the bacterial strain was carried out in $500 \mathrm{ml}$ incubating flask to get mass production of the growing cells.

\section{- Rats:}

Male Westar rats $(\mathrm{n}=30)$, with an initial mean weight of $170 \pm 10 \mathrm{~g}$ were obtained from vaccine and immunity organization Helwan Farm, Cairo, Egypt. The animals were housed in individual metabolic cages and fed a pelleteddiet at the age of 40 day. After 5 days as adaptation period, rats were randomly dividedinto three groups, a control group, a FOS group and FOS with probiotic bacteria (Lactobacillus acidophilus) group $(n=10$ of each group). The diet in the FOS and FOS with Lactobacillus acidophilus groups contained $5 \mathrm{~g} / 100 \mathrm{~g}$ inulin and $2.5 \mathrm{~g} / 100 \mathrm{~g}$ diet respectively, throughreplacement of the sucrose in the control diet, which wasprepared according to the formulation [14]. The diet was introduced to the rats in special food cups to avoid scattering of food. Food and water were provided ad-libitum and checked daily. The powdered diets were mixed with an equal amount ofpurified water. The respective wet diets were dried for $1 \mathrm{~d}\left(80^{\circ} \mathrm{C}\right)$ to calculate the wet/dry ratio, and calcium concentrationsin the dry diets were then measured [15]. The control, FOS and FOS with probiotic bacteria diets contained5.21 and $5.18 \mathrm{~g} / \mathrm{kg}$ dry diet of calcium. All of the rats werefed a constant amount of calcium $(90 \mathrm{mg} / \mathrm{d})$ in their respective dietsthroughout the experiment, beginning when they were 45 day old.

\section{- A mineralmetabolic:}

A mineralmetabolic study was performed to determine apparent calciumand magnesium absorptions in the intestine. This study was performed 4 day before sacrificed (at 60 day of age) over a 5-day period. Feceswere collected on a sheet of decalcified filter paper, ashless $640^{\circ} \mathrm{C}, 3$ day) and then dissolved in $2.0 \mathrm{~mol} / \mathrm{L} \mathrm{HCl}$. Finalbody weight and food consumption during the metabolic studywere recorded. The calcium and magnesium in feces were determinedusing an atomic absorption spectrophotometer (Perkin Elmer,Norwalk, CT). Apparent intestinal calcium and magnesium absorptionswere calculated.

After rats were sacrificed, the right femur from each rat was removed immediatelyand fixed in $70 \%$ ethanol. The neck of the femoral head was cross-sectioned. These sections were polishedwith alumina particles on a polishing cloth then mineral concentrationsin local bone areas was measured by the use of the technique according to [16]. The mineral concentrations $(\mathrm{Ca}, \mathrm{Mg}$, and $\mathrm{P})$ were measured and mean values were calculated. 


\section{- Blood samples:}

It was collected from each rat from the right arm and then separated by centrifugation. Separated serum samples have been kept frozen till antibodies estimation at the end of the experiment duration.

\section{- Antibodies assessment:}

Serum anti-sporidiumIgG and IgM were determined by ELISA standard technique according to the method of Knowlton et al., [17]. All assessed antibodies were expressed as U/ml.

\section{- Statically analysis:}

Data are expressed as means and SD. Statistical analyses wereperformed using the SPSS statistical software package (SPSS version6.0, SPSS, Chicago, IL). An unpaired Student's $t$ testwas used to identify differences between the control and FOS groups.Pearson's correlation coefficient was calculated to analyze therelationship between apparent calcium absorption and calcium concentrationin the bone surface. Differences were considered significantat $\mathrm{P}<0.01$.

\section{Results \& Discussion}

The gain in body weight in the FOS with probiotic bacteria group $(98 \pm 3 \mathrm{~g})$ diddiffer significantly from that in the control group $(74 \pm 9 \mathrm{~g})$. Rats inthe control and FOS with probiotic bacteria groups consumed $>86$ and $115 \%$ of theirfood supply, respectively. Prebiotics act in intestines; they have a profound effect on the pathogens and bad bacteria in body that can cause disease. Probiotic support healthy digestion and increase defecation and reduce constipation. It's important to remember that both probiotics and prebiotics work together, synergistically [12].

The present results go in the same lines with reported by Mountzouris et al., [18] who reported that ingested dietary probiotic bacteria with oligosaccharides could involve in modulation of nutritional status in human with a significant improvement of the general health status. In addition, incorporation of the dietary probiotic bacteria with dietary fructooligosaccharide could offer a significant improvement and protection against many forms of gastrointestinal diseases caused by several forms of microorganisms. This finding is highly agreed with Duggan et al., [19] reports. The results of Wendakoon et al., [20]indicated that ingestion of probiotic bacteria is associated highly with the protection against gastric ulcers in human.

Therefore, calcium intake in thecontrol group, calculated from food consumption and calciumconcentrations in the diet, was similar to that in the OEI with probiotic bacteria group $(\sim 90 \mathrm{mg} / \mathrm{d}$ in each group).

From table (1) found that both calcium and magnesium apparentabsorption was slightly but significantly greater in rats fed the FOS and probiotic bacteria. The fractional absorption of these mineralsin the FOS with probiotic bacteria group was also significantly higher than that in either control or FOS groups.

Ellegärd et al, [21], reported that the no digestible carbohydrates (dietary fiber) have been reported to impair the small-intestinal absorption of minerals because of their binding or sequestering action. However, the minerals that are bound or sequestered and, consequently, not absorbed in the small intestine, do reach the colon, where they may be released from the carbohydrate matrix and absorbed.

Moreover, a high concentration of short-chain carboxylic acids resulting from the colonic fermentation of the no digestible carbohydrates facilitates the colonic absorption of minerals, particularly $\mathrm{Ca} 2+$ and $\mathrm{Mg} 2+$. In addition, independent of any binding or sequestering of minerals, some no digestible carbohydrates (eg, inulintype fructans) may improve mineral absorption and balance because of an osmotic effect that transfers water into the large bowel, thus increasing the volume of fluid in which these minerals can dissolve.

An interaction between calcium and magnesium has been reported. Briefly,reduced magnesium absorption occurs due to a high calcium intake[22]. In addition, calcium suppresses magnesiumsolubility in the ileal lumen and lowers magnesium absorptionin vitro [23]. However, in this study, calciumand magnesium absorptions were enhanced simultaneously in FOS -fedrats. Similar effects on mineral absorption have been reportedby other investigators [24]. Considering theeffect of FOS on mineral absorption, results would expect that calciumand magnesium are used for calcification. In fact, the weightpercent of these minerals were enhanced, as calculated froma small area $(7.5 \times 10 \mu \mathrm{m})$ on the cortex or trabecularbone. Calcium in bone is usually characterized as hydroxyapatite $\left[\left(\mathrm{Ca}_{10}\left(\mathrm{PO}_{4}\right)_{6}(\mathrm{OH})_{2}\right)\right]$ [25]. Magnesium has been shown to bind to the surface of hydroxyapatitecrystals and to retard the nucleation and growth of hydroxyapatitein vitro [26]. In fact, rats fed excess magnesiumhave smaller mineral crystals in their bone than control, pair-fedrats. In contrast, the hydroxyapatite crystals in magnesium-deficientrats are significantly augmented [27, 28]. Thus, the enhanced weight percent of calciumand magnesium might be associated with hydroxyapatite crystalsize.

FOS consumption enhances calcium retention resulting from stimulatedcalcium absorption [29]. Dietary FOS alsostimulates magnesium absorption and enhances its balance [24, 30 and 31]. 
Data presented in tables $(2 \& 3)$ indicated that the both trabecular bone volume probiotic bacteria fed rats were significantly greater than those in both control and FOS groups. Bone area in the middle diaphysis in the FOS -probiotic bacteria group washighly different from that in the control group. Eitheraugmented trabecular bone or an expanded epiphyseal cartilage plateis found when \% TBV is enhanced [32, 33]. However, in this study, no abnormalities in bonestructure were found in rats fed the FOS diet.In this study,probiotic bacteria had an improvement effects on mineral absorption and retention. Considering previousreports and present results, the extra calcium and magnesium absorbedin the intestine as a result of probiotic bacteria consumption is likely to beretained in bone and other tissues of the body.

In this experiment, measured the volume ofsecondary spongiosa (\% TBV) in the metaphysis, which was slightlybut significantly enhanced in rats fed FOS. Also result observedan enhancement of bone volume in the femoral neck containingcortex and marrow trabecular. An increased \% TBV is usuallyobserved in rats when bone resorption is therapeutically or toxicallyinhibited by substances such as bisphosphonates or strontium [32, 34].

In table (3) showed that Phosphorus, magnesium and calcium concentrations in different bone surfaces of the femur in different rats groups. The findings were a significant between FOS with probiotics group and control group in all parameter.

On the other hand, Fountoset al.[35] suggested thatin vivo measurements of the calcium/phosphorus ratio of bonemay be useful for assessing skeletal aging or some bone diseases.However, in this study, there were no differences in this ratioin the regions examined. Thus, FOS consumption might slightlyenhance mineral concentrations under physiologic conditions.

The mineral concentrations in the femoral bone site, which were consideredto have been well formed and developed after dietary treatment [36], were enhanced by FOS -probiotic bacteria consumption. Similareffects were found in other regions that were close to the surfaceof trabecular bone. In addition, the calcium/phosphorus ratio didnot differ between groups. There was a significant relationship betweenabsorbed calcium in the intestine and calcium concentrationin bone $(\mathrm{P}<0.005)$, and a similar relationshipwas found for magnesium $(\mathrm{P}<0.005)$.

In summary, this is the first report to address the effect of probioticbacteria on bone structure and local mineral concentrations in addition to the general immunological indices in growingrats was highly noticed. The loss of both cortical and trabecular bone is believedto contribute to decreased bone strength [37]. In particular, the femoral neck is thought to bean important site for osteoporotic bone loss in humans [38]. Peak bone mass in humans is achieved aftersexual maturity and is then maintained for two decades. Thereafter, the mass of virtually all bones declines until death. Thus, it has been established that calcium deposition in bone in thegrowing stage contributes to the prevention of age-related bonediseases.

'The results in table (4) observed effects of FOS with probiotics bacteria onimmunological of deferent rats groups. All evaluate immunological parameter showed that group rat fed inline and Lactobacillus acidophilus strain was significant compare control group and group fed only inulin. Probiotics may act directly or indirectly on the colonizing gut microbiota, thereby positively impacting human health. Probiotics have been shown to inhibit the growth of pathogens through the production of antimicrobial substances, and to bolster the epithelial barrier function. They contribute to sustaining the host immune response and have metabolic and digestive functions, such as reducing cholesterol levels and synthesizing folate and vitamin B12 [39]. Preclinical data have shown that probiotic microorganisms can have anti-inflammatory effects and may exert neuromodulator effects that moderate response to stress[40]. In addition, these multiple mechanisms of action provide an explanation for many of the GI benefits observed, but may also explain the potential for numerous extra-intestinal benefits, such as reduction of incidence or duration of some acute respiratory diseases, [41]pain perception, [42]and improved therapeutic efficacy of drugs to treat bacterial vaginitis $[\mathbf{4 1 , 4 3 ]}$.

Mechanisms include [44] competition for dietary ingredients as growth substrates, [45] bioconversion of, for example, sugars into fermentation products with inhibitory properties, (Williams, et al., [46]production of growth substrates for other bacteria (ie, vitamins), (Guarner, et al.,[47]direct antagonism by bacteriocins, NCCAM, [48] competitive exclusion for binding sites, ISAPP, [49] improved barrier function, Sanders, et al., [50]reduction of inflammation that alters intestinal properties for colonization within, and stimulation of innate immune response by unknown mechanisms. IEC, intestinal epithelial cells; DC, dendritic cells; T, T cells; TGF, transforming growth factor; IL, interleukin; B, Bcell; Tn, neutrophil regulating T cell; Th, helper T cell; T17, T cells producing IL17;Treg, regulatory T cell. 


\section{Tables}

Table (1): Mean \pm SD, apparent calcium (Ca) and magnesium (Mg) absorptions and their fractional absorption rates in different rats groups

\begin{tabular}{|l|c|c|c|}
\hline \multicolumn{1}{|c|}{ Mineral absorption } & $\begin{array}{c}\text { Control } \\
(\mathbf{n = 8})\end{array}$ & $\begin{array}{c}\text { FOS } \\
(\mathbf{n}=\mathbf{8})\end{array}$ & $\begin{array}{c}\text { FOS + Probiotic } \\
(\mathbf{n = 8})\end{array}$ \\
\hline Apparent Ca absorption, mg/d & $42.63 \pm$ & $50.58 \pm$ & $59.61 \pm$ \\
& 2.111 & $5.77^{\mathrm{a}}$ & $2.77^{\mathrm{a}}$ \\
\hline Apparent Mg absorption, mg/d & $4.33 \pm$ & $5.41 \pm$ & $5.38 \pm$ \\
& 0.45 & $0.19^{\mathrm{a}}$ & $0.10^{\mathrm{a}}$ \\
\hline Fractional Ca absorption rate, \% & $41.20 \pm$ & $53.24 \pm$ & $58.20 \pm$ \\
& 6.20 & $6.08^{\mathrm{a}}$ & $6.01^{\mathrm{a}}$ \\
\hline Fractional Mg absorption rate, \% & $48.10 \pm$ & $67.85 \pm$ & $72.11 \pm$ \\
& 2.40 & $2.45^{\mathrm{a}}$ & $1.33^{\mathrm{a}}$ \\
\hline
\end{tabular}

${ }^{a}$ Significantly different from the control group $(\mathrm{P}<0.05)$.

Table 2: Means \pm SD, bone morphometric measured at the femoral neck and middle diaphysis (cross sections) and at the metaphysis (sagittal section) in different rats groups

\begin{tabular}{|l|c|c|c|}
\hline \multicolumn{1}{|c|}{ Bone Site } & $\begin{array}{c}\text { Control } \\
(\mathbf{n = 8})\end{array}$ & $\begin{array}{c}\text { FOS } \\
(\mathbf{n}=\mathbf{8})\end{array}$ & $\begin{array}{c}\text { FOS with Probiotic } \\
(\mathbf{n}=\mathbf{8})\end{array}$ \\
\hline $\mathbf{B V}^{\mathbf{2}}$ in the neck, \% & $70.7 \pm$ & $78.3 \pm$ & $82.6 \pm$ \\
& 2.10 & $1.82^{\mathrm{a}}$ & $1.12^{\mathrm{a}}$ \\
\hline BA in the middle diaphysis, $\mathbf{~ m m}^{\mathbf{2}}$ & $3.8 \pm$ & $4.2 \pm$ & $5.8 \pm$ \\
& 0.14 & 0.14 & 0.33 \\
\hline TBV in the metaphysis, \% & $30.1 \pm$ & $35.6 \pm$ & $39.6 \pm$ \\
& 1.03 & $4.91^{\mathrm{a}}$ & $2.11^{\mathrm{a}}$ \\
\hline
\end{tabular}

${ }^{\text {a }}$ Significantly different from the control group $(\mathrm{P}<0.05)$.

${ }^{2} \mathrm{BV}$, bone volume;

$\mathrm{BA}$, bone area;

TBV, trabecular bone volume.

Table 3: Means \pm SD, Phosphorus, magnesium and calcium concentrations measured by $X$-ray microanalysis in different bone surfaces of the femur in different rats groups

\begin{tabular}{|c|c|c|c|}
\hline Bone Site & $\begin{array}{c}\text { Control } \\
(\mathrm{n}=8)\end{array}$ & $\begin{array}{c}\text { FOS } \\
(\mathrm{n}=8)\end{array}$ & $\begin{array}{c}\text { FOS + } \\
\text { Probiotic } \\
(n=8)\end{array}$ \\
\hline \multicolumn{4}{|l|}{ Neck g/100 g } \\
\hline Phosphorus & $11.09 \pm 0.16$ & $11.54 \pm 0.18$ & $12.54 \pm 0.18$ \\
\hline Magnesium & $0.57 \pm 0.05$ & $0.57 \pm 0.03^{\mathrm{a}}$ & $0.87 \pm 0.03^{\mathrm{a}}$ \\
\hline Calcium & $21.92 \pm 0.26$ & $23.92 \pm 0.32^{\mathrm{a}}$ & $26.92 \pm 0.32^{\mathrm{a}}$ \\
\hline $\mathrm{Ca} / \mathrm{P}, \mathrm{g} / \mathrm{g}$ & $2.15 \pm 0.01$ & $2.05 \pm 0.01$ & $2.28 \pm 0.01$ \\
\hline \multicolumn{4}{|l|}{ Diaphysis } \\
\hline Phosphorus & $19.89 \pm 0.23$ & $11.57 \pm 0.24^{\mathrm{a}}$ & $12.87 \pm 0.24^{\mathrm{a}}$ \\
\hline Magnesium & $0.46 \pm 0.04$ & $0.53 \pm 0.07^{b}$ & $0.69 \pm 0.07^{b}$ \\
\hline Calcium & $22.81 \pm 0.44$ & $23.74 \pm 0.52^{\mathrm{a}}$ & $25.92 \pm 0.52^{\mathrm{a}}$ \\
\hline $\mathrm{Ca} / \mathrm{P}, \mathrm{g} / \mathrm{g}$ & $2.03 \pm 0.01$ & $2.25 \pm 0.01$ & $3.01 \pm 0.01$ \\
\hline \multicolumn{4}{|l|}{ Metaphysis } \\
\hline Phosphorus & $10.51 \pm 0.10$ & $11.24 \pm 0.21^{\mathrm{a}}$ & $12.70 \pm 0.21^{\mathrm{a}}$ \\
\hline Magnesium & $0.55 \pm 0.02$ & $0.71 \pm 0.06^{\mathrm{a}}$ & $0.80 \pm 0.06^{\mathrm{a}}$ \\
\hline Calcium & $23.21 \pm 0.29$ & $24.88 \pm 0.42^{\mathrm{a}}$ & $26.06 \pm 0.42^{\mathrm{a}}$ \\
\hline $\mathrm{Ca} / \mathrm{P}, \mathrm{g} / \mathrm{g}$ & $2.03 \pm 0.01$ & $2.47 \pm 0.01$ & $3.17 \pm 0.01$ \\
\hline
\end{tabular}

${ }^{\mathrm{a}, \mathrm{b}}$ Significantly different from the control group (a, b; $\mathrm{P}<0.05, \mathrm{P}<0.01$ ).

Table 4- Increased level of immunological indices as affected by dietary consumption of probiotic bacteria with inulin

\begin{tabular}{|c|c|c|c|c|}
\hline \multirow{2}{*}{$\begin{array}{l}\text { Immunity } \\
\text { Indices }\end{array}$} & \multicolumn{4}{|c|}{ Rat Groups } \\
\hline & $\begin{array}{c}\text { Control } \\
(\mathrm{n}=8)\end{array}$ & $\begin{array}{c}\text { OEI } \\
(n=8)\end{array}$ & $\begin{array}{c}\text { OEI + } \\
\text { Probiotic }(n=8) \\
\end{array}$ & $\mathbf{P}$ \\
\hline$\underline{\operatorname{IgG}}$ & $\mathbf{0}$ & 11.3 & $18.9^{\mathrm{a}}$ & $<0.01$ \\
\hline $\operatorname{IgM}$ & $\mathbf{0}$ & 15.5 & $22.5^{a}$ & $<0.01$ \\
\hline $\operatorname{IgA}$ & $\mathbf{0}$ & 11.8 & $19.7^{\mathrm{a}}$ & $<0.01$ \\
\hline $\mathrm{CD}^{+4}$ & $\mathbf{0}$ & 6.6 & $14.5^{\mathrm{a}}$ & $<0.01$ \\
\hline $\mathrm{CD}^{+8}$ & $\mathbf{0}$ & 8.2 & $17.4^{\mathrm{a}}$ & $<0.01$ \\
\hline
\end{tabular}


${ }^{a}$ Significantly different from the control group $(\mathrm{P}<0.01)$

\section{Conclusion}

Prebiotics ("good" bacteria promoters) and probiotics ("good" bacteria) work together synergistically. In other words, prebiotics are breakfast, lunch and dinner for probiotics, which restores and can improve GI health. Products that combine these together are called synbiotics. On the menu, that means enjoying bananas atop yogurt.

So be sure to include food sources of prebiotics and probiotics on your grocery shopping list, taking the time to double check labels when at the market. The bottom line: At minimum, prebiotics and probiotics are keys for good gut health. finding that the gut flora is responsible for more than just digestion."

Basically, incorporating health-promoting functional foods, such as foods containing prebiotics and probiotics, into the diet potentially aids in creating a healthier you.

So this study concluded that probiotic and prebioticintake together improved both mineral absorption and immunological status compare only prebiotic. Study recommended intake probiotics commonly consumed as part of fermented foods with specially added active live cultures, such as in yogurt, soy yogurt, or as dietary supplements with prebiotic, such as fructo-oligosaccharides (FOS), inulin, and galacto-oligosaccharides (GOS).:bananas, onions, garlic, leeks, asparagus, artichokes, soybeans and whole-wheat foods.

\section{Reference:}

[1]. Rijkers, Ger T.; De Vos, Willem M.; Brummer, Robert-Jan; Morelli, Lorenzo; Corthier, Gerard; Marteau, Philippe: "Health benefits and health claims of probiotics: Bridging science and marketing". British Journal of Nutrition, 2011 , 106 (9): $1291-6$.

[2]. World Gastroenterology Organisation (WGO),: Practice Guideline2008.

[3]. Consumer Lab.com: Product Review: Probiotics Supplements for Adults, Children and Pets. ConsumerLab.com, White Plains, NY 2009.

[4]. Sanders, M.E., Gibson, G., Gill, H.S., Guarner, F.: "Probiotics: Their Potential to Impact Human Health. Council for Agricultural Science and Technology,"2007 Issue Paper 36, CAST, Ames, IA.

[5]. Ljungh A, and Wadstrom T,: Lactobacillus Molecular Biology: From Genomics to Probiotics. Caister Academic Press. 2009ISBN 978-1904455417

[6]. Web MD :Probiotics \& Probiotic Supplements -: Uses and Safetyprobiotics and prebiotics, reviews2013.

[7]. Braat, H; Van Den Brande, J; Van Tol, E; Hommes, D; Peppelenbosch, M; Van Deventer, S: "Lactobacillus rhamnosus induces peripheral hyporesponsiveness in stimulated CD4+ T cells via", 2004.

[8]. University of Pennsylvania School of Medicine (UPSM):"Good' bacteria keep immune system primed to fight future infections" Science Daily2010.

[9]. European Food Safety Authority (EFSA): Committed since to ensuring that Europe's food is safe". Efsa.europa.eu. Retrieved 201211-08.

[10]. Food and Agriculture Organization of the United Nations; World Health Organization: Guidelines for the evaluation of probiotics in food: joint FAO/WHO Working Group report on drafting guidelines for the evaluation of probiotics in food, 2010.

[11]. World Gastroenterology Organization Global Guidelines (WGO), Probiotics and prebiotics, 2011.

[12]. American Dietetic Association (ADA), : Probiotics and Prebiotics Retrieved, 2010.

[13]. Gibson GR, Scott KP, Rastall RA, Tuohy KM, Hotchkiss A, Dubert-Ferrandon A, Gareau M, Murphy EF, Saulnier D, Loh G, Macfarlane S, Delzenne N, Ringel Y, Kozianowski G, Dickmann R, Lenoir-Wijnkoop I, Walker C, Buddington R.: Dietary prebiotics: Current status and new definition. IFIS Functional Foods, 2010Bulletin 7(1):1-19.

[14]. Reeves P. G., Nielsen F. H., Fahey G. C.: AIN-93 purified diets for laboratory rodents: final report of the American Institute of Nutrition ad hoc writing committee on the reformulation of the AIN-76A rodent diet. J. Nutr.,1993; 123:1939-1951

[15]. Morohashi T., Sano T., Ohta A., Yamada S.: True calcium absorption in the intestine is enhanced by fructooligosaccharide feeding in rats. J. Nutr, 1998; 128:1815-1818

[16]. Roschger P., Plenk H., Jr, Klaushofer K., Eschberger J.: A new scanning electron microscopy approach to the quantification of bone mineral distribution: backscattered electron image grey-levels correlated to calcium K alpha-line intensities. Scanning Microsc; $1995 ; 9: 75-88$

[17]. Knowlton, D. R.; Spector, D. M. and Word, R. L.: Development of an improved method for measuring neutralizing antibodies to rotavirus. J. Virol. Methods, 1991; 33: 127-13

[18]. Mountzouris, K.C., A.L. McCartney and R.G. Gibson,:Intestinal microflora of human infants and current trends for its nutritional modulation. Br. J. Nutr., 2002; 87: 405-420.

[19]. DUGGAN, C, GANNON, J \& WALKER WA.:Protective nutrients and functional foods for the gastrointestinal tract. American Journal of Clinical Nutrition, 2002; 75(5):789-808

[20]. Wendakoon, C. N., A. B. Thomson, and L. Ozime k.: Lack of therapeutic effect of a specially designed yogurt for the eradication of Helicobacter pylori infection. Digestion, 2002; 65:16-20.

[21]. Ellegärd L, Andersson H, Bosaeus I.: Inulin and oligofructose do not influence the absorption of cholesterol or the excretion of cholesterol, Ca, Mg, Zn, Fe, or bile acids but increases energy excretion in ileostomy subjects. Eur J ClinNutr; 1997; 51:1-5.

[22]. Watkins D. W., Jahangeer S., Floor M. K., Alabaster O.: Magnesium and calcium absorption in Fischer-344 rats influenced by changes in dietary fibre (wheat bran), fat and calcium. Magnes. Res, 1992; 5:15-21

[23]. Brink E. J., Beynen A. C., Dekker P. R., van Beresteijn E. C., van der Meer R.: Interaction of calcium and phosphate decreases ileal magnesium solubility and apparent magnesium absorption in rats. J. Nutr.1992; 122:580-586

[24]. Ohta A., Baba S., Takizawa T., Adachi T.:Effects of fructooligosaccharides on the absorption of magnesium in the magnesiumdeficient rat model. J. Nutr. Sci. Vitaminol, 1994a.;40:171-180

[25]. Heaney R. P. Calcium, Bilezikian J. P. Raisz L. G. Rodan G. A.: Principle of Bone Biology,1996:1007-1018 Academic Press San Diego, CA.

[26]. Bigi A., Foresti E., Gregorini R., Ripamonti A., Roveri N., Shah J. S.: The role of magnesium on the structure of biological apatites. Calcif. Tissue Int., 1992; 50:439-444. 
[27]. Burnell J. M., Liu C., Miller A. G., Teubner E.: Effects of dietary alteration of bicarbonate and magnesium on rat bone. Am. J. Physiol, 1986; 250:F302-F307

[28]. Boskey A. L., Rimnac C. M., Bansal M., Federman M., Lian J., Boyan B. D.: Effect of short-term hypomagnesemia on the chemical and mechanical properties of rat bone. J. Orthop. Res, 1992; 10:774-783

[29]. Rio ME, Zago Beatriz L, and Garcia H, Winter L.: The nutritional status changes the effectiveness of a dietary supplement of lactic bacteria on the emergence of respiratory tract diseases in children. Arch LatinoamNutr;2002, 52:29-34 [in Spanish].

[30]. Ohta A., Baba S., Ohtsuki S., Taguchi A., and Adachi T., Hara H.:Prevention of coprophagy modifies magnesium absorption in rats fed with fructo-oligosaccharides. Br. J. Nutr. 1996; 75:775-784

[31]. Ohta A., Baba S., Ohtsuki M., Takizawa T., Adachi T., Hara H.: In vivo absorption of calcium carbonate and magnesium oxide from the large intestine in rats. J. Nutr. Sci. Vitaminol., 1997; 43:35-46

[32]. Morohashi T., Izumisawa T., and Matsumoto A., Yamada S. (): The effects of stable strontium on calcium metabolism: I. Kinetic analysis of calcium metabolism in strontium-fed rats. J. Bone Miner. Met, 1993; 11:31-38

[33]. Wronski T. J., Yen C. F., Qi H., Dann L. M.:Parathyroid hormone is more effective than estrogen or bisphosphonates for restoration of lost bone mass in ovariectomized rats. Endocrinology, 1993; 132:823-831

[34]. Mühlbauer R. C., Bauss F., Schenk R., Janner M., Bosies E., Strein K., Fleisch H.: A potent new bisphosphonate to inhibit bone resorption. J. Bone Miner. Res.1991;6:1003-1011

[35]. Fountos G., Tzaphlidou M., Kounadi E., Glaros D. : In vivo measurement of radius calcium/phosphorus ratio by X-ray absorptiometry. Appl. Radiat. Isot, 1999; 51:273-278

[36]. Morohashi T., Sano T., Harai K., Yamada S.: Effects of strontium on calcium metabolism in rats II. Strontium prevents the increased rate of bone turnover in ovariectomized rats. Jpn. J. Pharmacol, 1995; 68:153-159

[37]. Søgaard C. H., Wronski T. J., McOsker J. E., Mosekilde L.: The positive effect of parathyroid hormone on femoral neck bone strength in ovariectomized rats is more pronounced than that of estrogen or bisphosphonates. Endocrinology, 1994; 134:650-657

[38]. Boyce T. M. and Bloebaum R. D. (): Cortical aging differences and fracture implications for the human femoral neck. Bone, $1993 ; 14: 769-778$

[39]. Holmes E, Kinross J, Gibson GR, et al.,:Therapeutic modulation of microbiota-host metabolic interactions. Science Transl Med, 2012.; 4(137):137rv136.

[40]. Ciorba MA. A.:Gastroenterologist's Guide to Probiotics. ClinGastroenterolHepatol, 2012;10(9):960-968.

[41]. Lenoir-Wijnkoop I, Sanders ME, Cabana MD, et al.,: Probiotic and prebiotic influence beyond the intestinal tract. Nutr Rev, 2007; 65(11):469-489.

[42]. Konturek PC, Brzozowski T, Konturek SJ.: Stress and the gut: pathophysiology, clinical consequences, diagnostic approach and treatment options. J PhysiolPharmacol,2011; 62(6):591-599.

[43]. Senok AC, Verstraelen H, Temmerman M, Botta GA.: Probiotics for the treatment of bacterial vaginosis. Cochrane Database Syst Rev.,2009; (4):CD006289.

[44]. Report of a Joint FAO/WHO: Expert Consultation on Evaluation of Health and Properties of Probiotics in Food Including Powder Milk with Live Lactic Acid Bacteria.2012,Córdoba, Argentina,

[45]. National Center for Complementary and Alternative Medicine (NCCAM): Oral probiotics: An introduction, 2012.

[46]. Williams MD, Ha CY and Ciorba MA.: Probiotics as therapy in gastroenterology: a study of physician opinions and recommendations. J ClinGastroentero, 2010; 44(9):631-636.

[47]. Guarner F, Khan AG, Garisch J, et al.: World gastroenterology organisation global guidelines: probiotics and prebiotics, October 2011. J ClinGastroenterol2012; 46(6):468-481.

[48]. National Center for Complementary and Alternative Medicine (NCCAMM),: Using dietary supplements wisely, 2012.

[49]. International Scientific Association for Probiotics and Prebiotics (ISAPP): Probiotics: A consumer guide to making smart choices. www.isapp.net. Updated March 11, 2009. Accessed July 16, 2012.

[50]. Sanders ME, Heimbach JT, Pot B, et al. (): Health claims substantiation for probiotic and prebiotic products. Gut Microbes, 2011; 2(3):127-133. 